\title{
A Drosophila genetic model of nephrolithiasis: transcriptional changes in response to diet induced stone formation

Vera Y. Chung ${ }^{*}$ and Benjamin W. Turney

\begin{abstract}
Background: Urolithiasis is a significant healthcare issue but the pathophysiology of stone disease remains poorly understood. Drosophila Malpighian tubules were known to share similar physiological function to human renal tubules. We have used Drosophila as a genetic model to study the transcriptional response to stone formation secondary to dietary manipulation.

Methods: Wild-type male flies were raised on standard medium supplemented with lithogenic agents: control, sodium oxalate ( $\mathrm{NaOx}$ ) and ethylene glycol (EG). At 2 weeks, Malpighian tubules were dissected under polarized microscope to visualize crystals. The parallel group was dissected for RNA extraction and subsequent nextgeneration RNA sequencing.

Results: Crystal formation was visualized in $20 \%( \pm 2.2)$ of flies on control diet, $73 \%( \pm 3.6)$ on $\mathrm{NaOx}$ diet and $84 \%( \pm 2.2)$ on EG diet. Differentially expressed genes were identified in flies fed with $\mathrm{NaOx}$ and $\mathrm{EG}$ diet comparing with the control group. Fifty-eight genes were differentially expressed (FDR $<0.05, p<0.05$ ) in NaOx diet and 20 genes in EG diet. The molecular function of differentially expressed genes were assessed. Among these, Nervana 3, Eaat1 (Excitatory amino acid transporter 1), CG7912, CG5404, CG3036 worked as ion transmembrane transporters, which were possibly involved in stone pathogenesis.

Conclusions: We have shown that by dietary modification, stone formation can be manipulated and visualized in Drosophila Malpighian tubules. This genetic model could be potentially used to identify the candidate genes that influence stone risk hence providing more insight to the pathogenesis of human stone disease.
\end{abstract}

\section{Background}

Urolithiasis is a major healthcare problem accounting for over 83,000 hospital attendances in the UK each year [1]. There is a high (around 10\%) lifetime prevalence of stone disease as well as recurrence rate worldwide [2]. In the last two decades, significant advance was made in the minimal invasive surgical treatment of stone disease. Effective medical therapies for prevention and treatment of stone disease are still lacking because little is known about the molecular pathophysiology of kidney stone disease.

Kidney stone is thought to be related to interaction of genetic factors and environment. In human renal stone disease, there are clear environmental influences including diet rich in animal protein, high salt intake, dehydration and obesity. Genetic predisposition to stone disease

\footnotetext{
* Correspondence: chungyeungvera@gmail.com

Oxford Stone Group, Department of Urology, Nuffield Department of Surgical Sciences, University of Oxford, Oxford, UK
}

is also well recognized. Approximately $25 \%$ of stone formers have a positive family history [3] but only a small minority have a monogenic cause such as cystinuria, Dent's disease or primary hyperoxaluria.

Overall, calcium oxalate $(\mathrm{CaOx})$ stones constitute the most common $(\sim 80 \%)$ stone type and are currently regarded as idiopathic in etiology. A systematic genetic study of $\mathrm{CaOx}$ stones excluded monogenetic inheritance but twin studies have estimated the heritability of kidney stones to be $56 \%[4]$.

In order to study the pathogenesis of human $\mathrm{CaOx}$ stone disease, various animal models have been established. Amongst these, Drosophila melanogaster has been proposed as a powerful translational model of human nephrolithiasis [5]. The advantages include similarity between Drosophila Malpighian tubule and human renal tubule, cost-effectiveness, convenience to observe crystals and relative ease to perform genetic manipulation. The 
Drosophila Malpighian tubules share similar features with human renal tubules in terms of physiological function, anatomical structure and genetic activity [5]. Flies are an unprotected species and can be acquired and maintained at low cost. Their short life cycle allows rapid observation of the effects of environmental alternation. Drosophila has been shown to readily form $\mathrm{CaOx}$ stones with dietary supplement of lithogenic agents within days [6]. Furthermore, the Drosophila genome is highly conserved and fully characterized. Extensive genomic tools are readily available to facilitate genetic manipulation in this versatile model organism. As such, we have used Drosophila as a genetic model to try to better understand the molecular pathophysiology of stone disease.

\section{Methods}

\section{Drosophila stocks}

Wild-type Drosophila melanogaster (Canton S strain) were raised in standard fly medium (composition: $72.3 \%$ water, $18.6 \%$ maize, $3.8 \%$ yeast, $2.2 \%$ soya, $3.1 \%$ agar) in a $25{ }^{\circ} \mathrm{C}, 50-60 \%$ humidity incubator. Only male flies were selected for the experiment.

\section{Lithogenic diets}

Three experimental diets were prepared: control group with standard fly medium, $0.05 \%$ Sodium oxalate $(\mathrm{NaOx})$ added to standard fly medium and $0.5 \%$ ethylene glycol (EG) added to standard fly medium. Biological triplicates were prepared in each group.

\section{Fly lifespan study}

New emergents were isolated on day 3 after eclosion under light anesthesia. They were randomly divided into 3 treatment groups. The starting population for each condition was 100 . The maintenance density was 25 flies per vial. Every 3 days the flies were transferred to fresh medium and numbers of dead flies were counted. Lifespan was recorded and subjected to survival analysis.

\section{Malpighian tubules preparation}

After 2 weeks of feeding on three different diets, the flies were killed on $\mathrm{CO}_{2}$ pad. The Malpighian tubules and hindgut were extracted in physiological medium (Schneider's drosophila medium.

Fifteen flies were dissected for each biological triplicate. Freshly dissected tubules and hindgut were prepared for polarized light microscopy examination. Parallel groups were dissected and processed for RNA extraction.

\section{Birefringence microscopy}

Malpighian tubules and hindgut were prepared fresh and observed under normal and polarized white light with an Olympus BX60 microscope. The percentage of crystal formation were documented and tubules were photographed.
The tubules with crystal formation were photographed and scaled.

\section{RNA extraction and quality control}

Total RNA was extracted from Malpighian tubules and hindgut of 15 flies in each biological replicate.

Qiagen MiRNeasy Mini Kit was used for RNA extraction.

RNA integrity was verified with Agilent 2100 Bioanalyzer (RNA 6000 Pico kit). Next generation RNA sequencing was performed and sequencing data was analyzed in collaboration with the Computational Biology Research Group using STAR (Spliced Transcripts Alignment to a Reference) and edgeR software.

\section{Statistics}

Statistical analyses were carried out with Prism biostatistical software (Graphpad, San Diego, CA).

\section{Results}

\section{Effect on lifespan}

The lifespan was significantly reduced by food enriched with $0.05 \% \mathrm{NaOx}$ and $0.5 \% \mathrm{EG}(p<0.0001)$ (Fig. 1$)$. The administration of EG had a more pronounced impact on the lifespan compared with $\mathrm{NaOx}(p<0.0001)$. The median and maximum lifespan in the control group was 43 and 64 days, 40 and 55 days in the $\mathrm{NaOx}$ diet, 31 and 52 days in the EG diet respectively.

\section{Inducing crystallization in Malpighian tubules}

The normal anatomy of Malpighian tubules is shown in Fig. 2. There are two pairs of Malpighian tubules in Drosophila: anterior and posterior pair. The two tubules joins into the ureter which then empties into the midgut

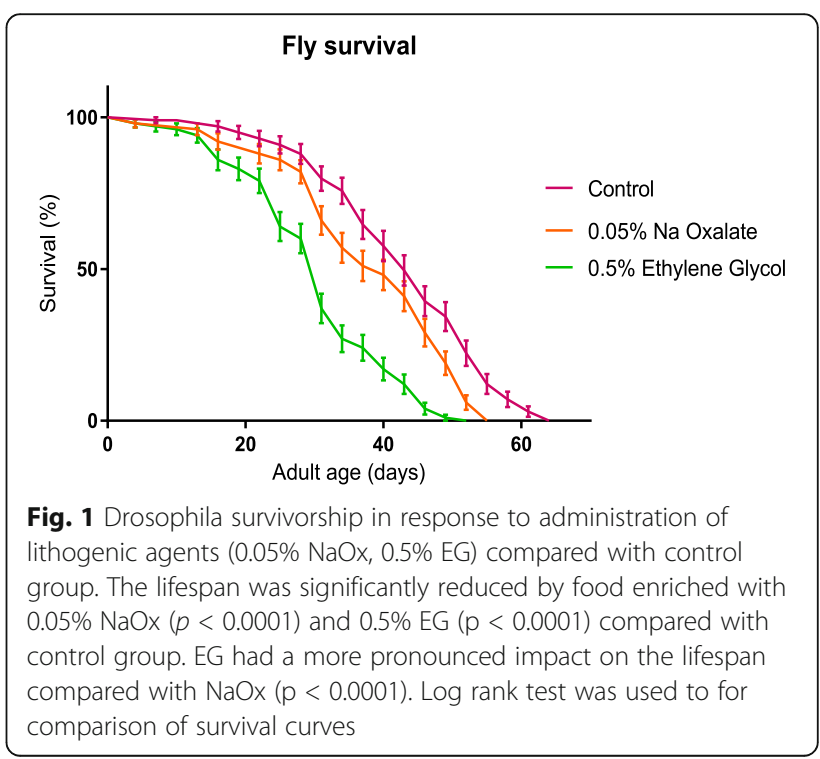




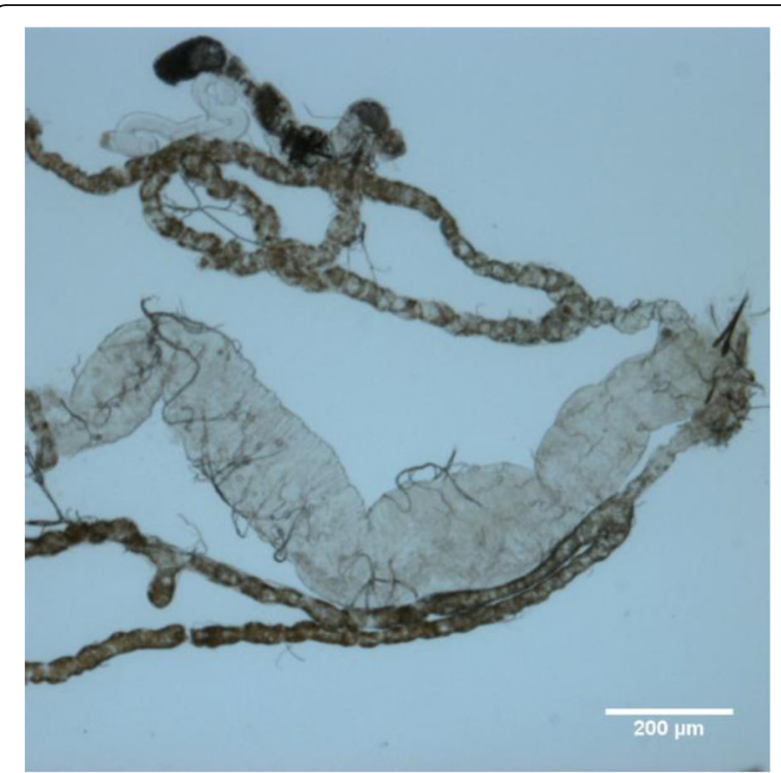

Fig. 2 Photograph of Malpighian tubules under 10x s magnification. Two pairs of Malpighian tubules coalesce into a common ureter which empty into the junction of midgut and hindgut

and hindgut junction. One Malpighian tubule measures about $2 \mathrm{~mm}$ long, with the inner diameter measuring about $50 \mathrm{um}$. Urine was generated via transport of ions, solutes followed by water across the tubular lumen, and sequentially excreted to the hindgut [5].

The concentration of lithogenic agents $(0.05 \%$ for $\mathrm{NaOx}$ and $0.5 \%$ for EG) was selected following optimization studies to adequately induce crystallization without leading to excessive premature death [6].

Crystal formation was detected as early as 1 week after initiation ingestion of lithogenic diets. Degree of crystallization was given a visual scale of $0,1+, 2+$, and $3+$ in each condition (Fig. 3) [6]. All scoring was performed by a single observer.

The birefringent crystals were most commonly visualized in the distal tubules. There were no crystals observed in the hindgut.. It was noticed that the crystal morphology in the $\mathrm{NaOx}$ group was small and extensive, in contrast to the more sizable and polyangular shape in the EG diet.

There was significantly $(p<0.003$ by chi-square test) higher rate of stone formation in the $\mathrm{NaOx}$ and EG diets (Table 1). Flies on control diet had a mean incidence of $20 \%$ stone formation whereas the incidence was $73 \%$ and $84 \%$ in $\mathrm{NaOx}$ and EG diets respectively. The incidence of crystal formation subcategorized to mild $(1+)$, moderate $(2+)$ and strong degrees (3+) was illustrated in Fig. 4.

\section{RNA sequencing and quality control}

The parallel group of experimental flies was dissected after 2 weeks on lithogenic diets. Malpighian tubules were processed for total RNA extraction. Quality of extracted RNA was verified by Nanodrop and Agilent 2100 Bioanalyzer. The electrophoretic ribosomal RNA (rRNA) profile of insects was different from the standard rRNA integrity benchmark. It was common to observe single rRNA peak in insect RNA which does not represent degradation [7]. The electrophoretic profile in Drosophila RNA could be explained by the fact that the $28 \mathrm{~s}$ rRNA was processed into two fragments that co-migrate with the $18 \mathrm{~s}$ rRNA. The RNA integrity in our samples was shown to be satisfactory with tight banding and no evidence of degradation (Fig. 5).

After verification of RNA integrity, next generation RNA sequencing was performed to sequence the whole transcriptome of 9 samples. The mRNA was extracted from the total RNA and subsequently converted to cDNA. Second strand cDNA synthesis incorporated dUTP. The cDNA was end-repaired, A-tailed and adapter-ligated. Samples underwent uridine digestion and then amplification. The prepared libraries were size selected, multiplexed before paired end sequencing over one lane of a flow cell.

\section{Sequenced genes and possible candidate genes}

Library preparations were analyzed by the Computational Biology Research Group, University of Oxford, UK. Differentially expressed genes with FDR (false detection rate) $<0.05$ and $p$-value $<0.05$ in all three biological triplicates were listed (Table 2). There were a total 58 genes identified in $\mathrm{NaOx}$ diet and 20 genes in EG diet. The mean expression level, Log Fold Change and $p$-Value of differentially expressed genes compared with control were displayed as smear plots and volcano plots (Fig. 6). Their molecular functions were matched in Flybase database and categorized (Fig. 7). Although there was no overlap between the differentially expressed genes in both treatment groups, their biological functions were very similar.

We identified those genes which function as transmembrane ion transporter that may be actively involved in in crystal formation. These potential candidate genes and their specific molecular functions were displayed in Table 3.

\section{Discussion}

The formation of kidney stones is likely the result of complicated interactions of multiple genetic factors in addition to environmental influence. In this model we have successfully induced $\mathrm{CaOx}$ crystals in Drosophila Malpighian tubules by diets enriched with lithogenic agents. Our study is the first to try to elucidate transcriptive changes in response to stone formation in the Drosophila model.

A previous pilot study on the experimental induction of lithogenic agents in Drosophila has shown that such diets had a negative impact on Drosophila survival in a dose dependent manner [6]. The crystal composition was analyzed by energy-disperse X-ray spectroscopy and 

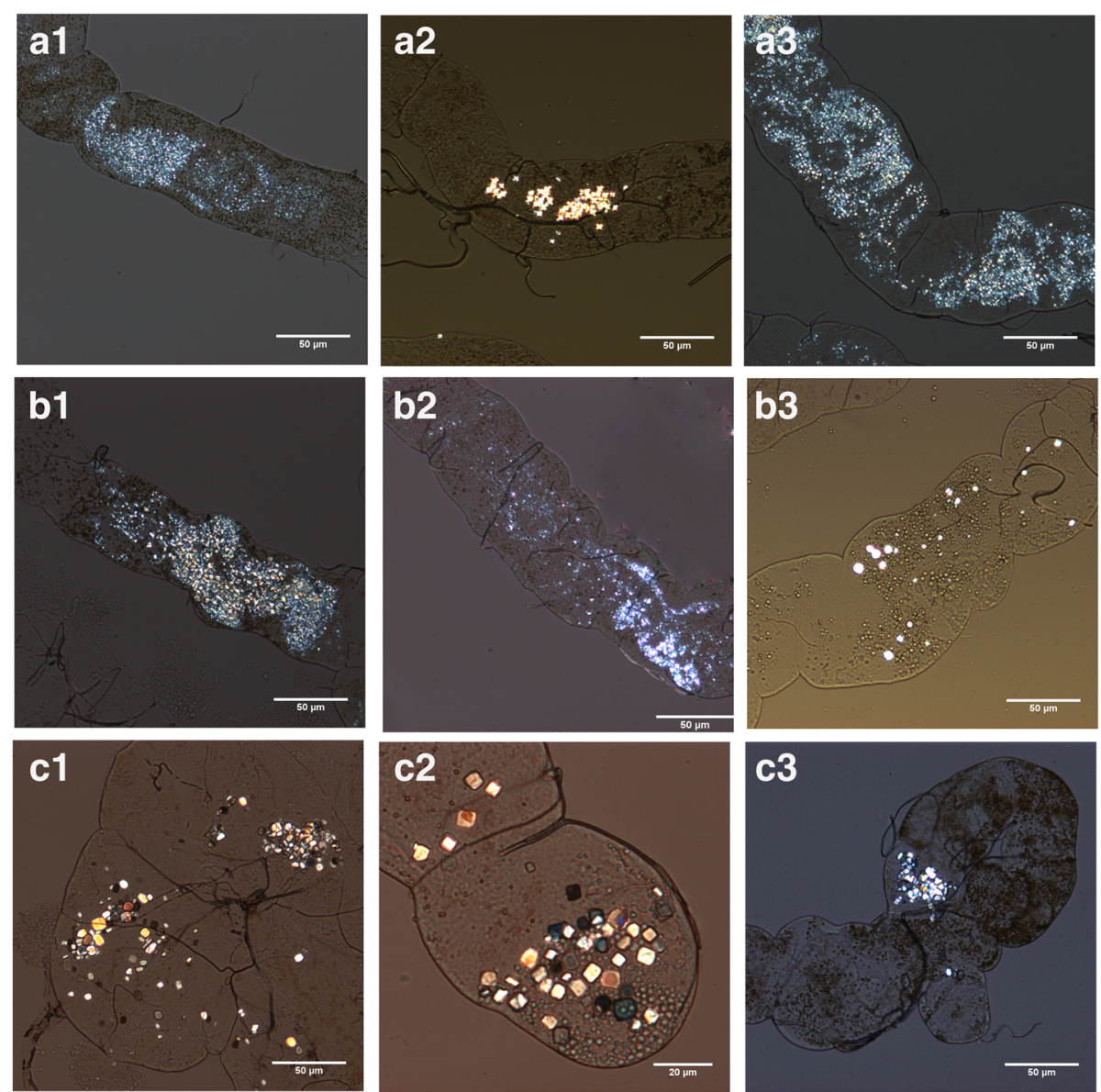

Fig. 3 Degree of crystal formation in Malpighian tubules by visual scale, 20x s magnification. 0: no stone formation, +: mild, 2+: moderate, 3+ strong crystal formation

scanning electron microscopy, which revealed predominantly $\mathrm{CaOx}$ monohydrate or $\mathrm{CaOx}$ dihydrate $[6,8]$.

Our survival study demonstrated in similar fashion that Drosophila's lifespan was significantly reduced by food enriched with $0.05 \% \mathrm{NaOx}$ and $0.5 \%$ EG. The overall incidence crystal formation in control flies in our experiment was higher (20\% vs $6.6 \%$ ) but slightly lower in the lithogenic diets ( $84 \%$ vs $94 \%$ ) compared with the pilot study.

Unlike the mammalian species, the Malpighian tubule in insects is the only organ for excreting solutes and water to the tubular lumen, as there is no glomerulus [9]. The distal segment of Malpighian tubules secretes

Table 1 Incidence of stone formation in Drosophila Malpighian tubules in 3 experimental conditions

\begin{tabular}{ll}
\hline Drosophila diet & Overall incidence of crystal formation (\%) \\
\hline control & $20 \pm 2.2$ \\
$0.05 \%$ sodium oxalate & $73 \pm 3.6$ \\
$0.5 \%$ ethylene glycol & $84 \pm 2.2$ \\
\hline
\end{tabular}

Values were expressed as means \pm standard error of mean

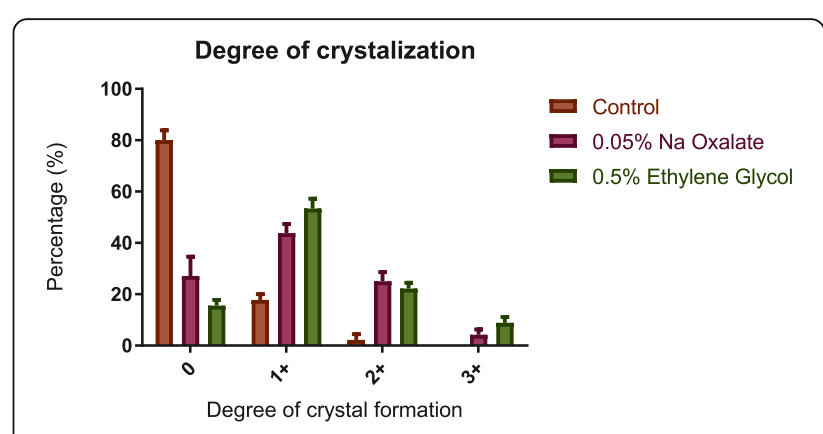

Fig. 4 Incidence of crystal formation according to degree of crystallization. The degree of crystallization was given a visual scale of $0,1+, 2+$ and $3+$ by a single observer. The incidence of crystal formation of the control group was $80 \%(0), 17.8 \%(1+)$ and $2.2 \%(2+)$ respectively. The incidence of crystal formation in flies fed on $\mathrm{NaOx}$ diet was $27 \%(0), 43.8 \%$ (1+), $25 \%(2+)$ and $4.2 \%(3+)$. In the EG cohort, the incidence was $15.6 \%(0)$, $53.3 \%(1+), 22.2 \%(2+), 8.9 \%(3+)$ respectively 


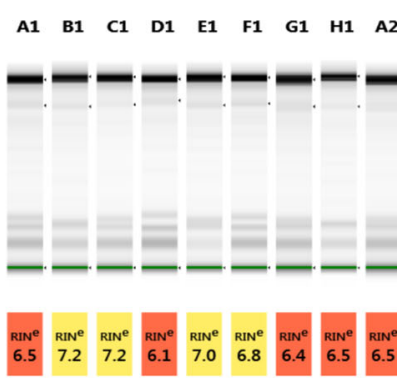

A1, B1, C1: biological triplicates of control diet

D1, E1, F1: biological triplicates of NaOx enriched diet

G1, H1, A2: biological triplicates of EG enriched diet

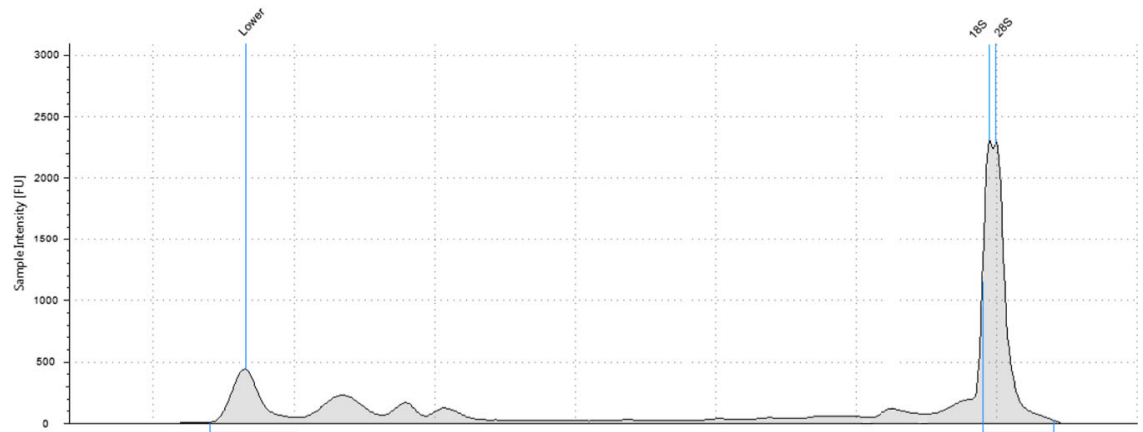

Fig. 5 RNA quality verification by Agilent 2100 Bio-analyzer. Gel image and electrophoretic profile of Drosophila Malpighian tubules RNA samples showed high quality RNA extraction. The electrophoretic ribosomal RNA profile of insects has single 285 peak which is commonly seen in insect RNA

electrolytes, organic solutes and water, and the proximal segments function as solute and water reabsorption [10]. The body calcium levels was regulated by Malpighian tubules by excretion through secretion into the lumen [11]. Administration of $\mathrm{NaOx}$ provides additional dietary supplement of oxalate, little evidence is available on how EG was metabolized in Drosophila however. Inferred from the metabolic pathway in the mammals, EG is degraded into four components: glycoaldehyde, glycolic acid, glyoxylic acid and oxalic acid. Excessive oxalic acid precipitates as $\mathrm{CaOx}$ stone in the tubules as a result [12]. The survival study demonstrated that the crystal accumulation in Malpighian tubules has a negative impact on the Drosophila lifespan, probably as a result of obstruction to the excretory organs and subsequent inability to maintain body hemostasis. EG induced a more profound negative impact on the lifespan, which could be related to associated metabolic acidosis [12] due to accumulated glycolic acid in addition to crystal formation.

Among the 58 differentially expressed genes in $\mathrm{NaOx}$ treatment group and 20 in EG group, we narrowed down the potential candidate genes by a number of criteria: molecular function, biological process and Log Fold changes compared with expression levels in the control group. There were no functionally significant overlapping genes between the two treatment groups, probably due to the fact that different biological pathways were involved in $\mathrm{NaOx}$ and EG diets. Genes that functions as transmembrane ion transporters had been singled out, namely Nervana 3, CG7912 and Eaat 1 in NaOx group; CG3036 and CG5404 in EG group. Crystallin coding for calcium ion binding protein and Dh44 which functions a diuretic hormone involved in body fluid secretion might also be of interest.

Nervana 3 codes for $\beta$ subunit of $\mathrm{Na}+/ \mathrm{K}+$ transporting ATPase, which catalyzes the hydrolysis of ATP coupled with the exchange of $\mathrm{Na}+$ and $\mathrm{K}+$ ions across the plasma membrane. The $\beta$ subunit regulates the transportation of sodium pumps to the plasma membrane [13]. $\mathrm{Na}+$ and $\mathrm{K}+$ transport has been implicated in $\mathrm{Ca} 2+$ ion across renal tubules and homeostasis [14]. Though there was no previous work to elucidate the role of $\mathrm{Na}+\mathrm{K}+$ pump in the Malpighian tubule, it was shown in rat and rabbit model that the basal-lateral plasma membrane contain $\mathrm{Na}+/ \mathrm{Ca} 2+$ exchange system which mediates the counter-transport of $\mathrm{Ca} 2+$ and $\mathrm{Na}+$ across the basal cell border $[15,16]$. A protein which functioned as $\mathrm{Na}+\mathrm{Ca} 2$ $+/ \mathrm{K}+$ exchanger has been described in Drosophila to promote $\mathrm{Ca} 2+$ extrusion from cells [17].

CG7912 is predicted to have the molecular function of high-affinity sulfate transmembrane transporter. Its function in Drosophila was inferred from homology to mammalian transporters. Presumably, it catalyzes the high affinity transfer of sulfate across the plasma membrane up its 
Table 2 Differentially expressed genes in $\mathrm{NaOx}$ and EG group compared with control

\begin{tabular}{|c|c|c|c|c|}
\hline & Gene ID & $\begin{array}{l}\text { Log Fold } \\
\text { Change }\end{array}$ & $P$ value & FDR \\
\hline $\begin{array}{l}\text { Sodium oxalate } \\
\text { group ( } 58 \text { genes) }\end{array}$ & 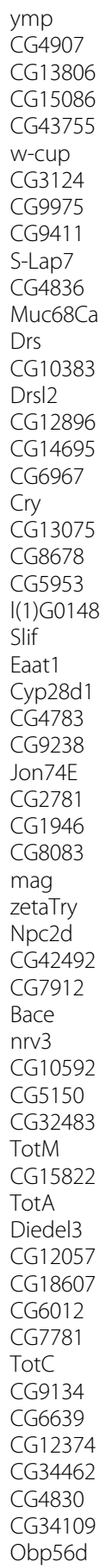 & $\begin{array}{l}4.10 \\
3.95 \\
3.03 \\
3.02 \\
2.80 \\
2.65 \\
2.63 \\
2.59 \\
2.50 \\
2.28 \\
2.10 \\
1.59 \\
1.40 \\
1.35 \\
1.35 \\
1.33 \\
1.17 \\
1.06 \\
0.95 \\
0.85 \\
0.84 \\
0.73 \\
-0.79 \\
-0.94 \\
-0.94 \\
-0.94 \\
-0.95 \\
-0.99 \\
-1.03 \\
-1.05 \\
-1.06 \\
-1.07 \\
-1.11 \\
-1.15 \\
-1.19 \\
-1.21 \\
-1.25 \\
-1.30 \\
-1.30 \\
-1.34 \\
-1.37 \\
-1.41 \\
-1.42 \\
-1.43 \\
-1.46 \\
-1.52 \\
-1.52 \\
-1.60 \\
-1.64 \\
-1.68 \\
-1.70 \\
-1.95 \\
-2.64 \\
-2.94 \\
-3.00 \\
-3.05 \\
-3.09 \\
-3.90\end{array}$ & $\begin{array}{l}2.46 \mathrm{E}-04 \\
3.08 \mathrm{E}-04 \\
2.97 \mathrm{E}-04 \\
1.10 \mathrm{E}-05 \\
1.79 \mathrm{E}-04 \\
5.88 \mathrm{E}-05 \\
8.60 \mathrm{E}-06 \\
1.60 \mathrm{E}-04 \\
3.06 \mathrm{E}-04 \\
2.21 \mathrm{E}-04 \\
2.04 \mathrm{E}-04 \\
1.62 \mathrm{E}-05 \\
1.20 \mathrm{E}-04 \\
3.85 \mathrm{E}-08 \\
1.09 \mathrm{E}-05 \\
6.96 \mathrm{E}-05 \\
2.29 \mathrm{E}-05 \\
7.99 \mathrm{E}-05 \\
8.28 \mathrm{E}-06 \\
1.63 \mathrm{E}-04 \\
6.20 \mathrm{E}-06 \\
2.58 \mathrm{E}-04 \\
6.09 \mathrm{E}-05 \\
1.85 \mathrm{E}-05 \\
7.78 \mathrm{E}-05 \\
6.84 \mathrm{E}-05 \\
1.07 \mathrm{E}-04 \\
3.32 \mathrm{E}-05 \\
9.67 \mathrm{E}-05 \\
1.54 \mathrm{E}-04 \\
1.57 \mathrm{E}-04 \\
5.32 \mathrm{E}-08 \\
4.66 \mathrm{E}-05 \\
8.53 \mathrm{E}-05 \\
6.69 \mathrm{E}-09 \\
8.67 \mathrm{E}-05 \\
2.44 \mathrm{E}-05 \\
6.24 \mathrm{E}-07 \\
2.79 \mathrm{E}-06 \\
3.06 \mathrm{E}-11 \\
1.16 \mathrm{E}-11 \\
9.60 \mathrm{E}-07 \\
9.48 \mathrm{E}-05 \\
1.36 \mathrm{E}-04 \\
4.46 \mathrm{E}-06 \\
5.61 \mathrm{E}-10 \\
4.76 \mathrm{E}-06 \\
1.50 \mathrm{E}-05 \\
3.45 \mathrm{E}-06 \\
5.05 \mathrm{E}-06 \\
2.89 \mathrm{E}-06 \\
6.57 \mathrm{E}-05 \\
1.50 \mathrm{E}-05 \\
5.04 \mathrm{E}-30 \\
3.27 \mathrm{E}-05 \\
1.47 \mathrm{E}-06 \\
2.51 \mathrm{E}-05 \\
1.61 \mathrm{E}-13\end{array}$ & $\begin{array}{l}4.27 \mathrm{E}-02 \\
4.99 \mathrm{E}-02 \\
4.99 \mathrm{E}-02 \\
4.69 \mathrm{E}-03 \\
3.30 \mathrm{E}-02 \\
1.67 \mathrm{E}-02 \\
4.04 \mathrm{E}-03 \\
3.07 \mathrm{E}-02 \\
4.99 \mathrm{E}-02 \\
3.92 \mathrm{E}-02 \\
3.68 \mathrm{E}-02 \\
6.09 \mathrm{E}-03 \\
2.50 \mathrm{E}-02 \\
5.17 \mathrm{E}-05 \\
4.69 \mathrm{E}-03 \\
1.77 \mathrm{E}-02 \\
7.95 \mathrm{E}-03 \\
1.92 \mathrm{E}-02 \\
4.04 \mathrm{E}-03 \\
3.07 \mathrm{E}-02 \\
3.24 \mathrm{E}-03 \\
4.40 \mathrm{E}-02 \\
1.68 \mathrm{E}-02 \\
6.67 \mathrm{E}-03 \\
1.92 \mathrm{E}-02 \\
1.77 \mathrm{E}-02 \\
2.29 \mathrm{E}-02 \\
1.01 \mathrm{E}-02 \\
2.11 \mathrm{E}-02 \\
3.07 \mathrm{E}-02 \\
3.07 \mathrm{E}-02 \\
6.24 \mathrm{E}-05 \\
1.37 \mathrm{E}-02 \\
1.99 \mathrm{E}-02 \\
1.05 \mathrm{E}-05 \\
1.99 \mathrm{E}-02 \\
8.12 \mathrm{E}-03 \\
6.51 \mathrm{E}-04 \\
2.09 \mathrm{E}-03 \\
7.20 \mathrm{E}-08 \\
3.64 \mathrm{E}-08 \\
9.01 \mathrm{E}-04 \\
2.11 \mathrm{E}-02 \\
2.79 \mathrm{E}-02 \\
2.79 \mathrm{E}-03 \\
1.05 \mathrm{E}-06 \\
2.79 \mathrm{E}-03 \\
5.89 \mathrm{E}-03 \\
2.31 \mathrm{E}-03 \\
2.79 \mathrm{E}-03 \\
2.09 \mathrm{E}-03 \\
1.76 \mathrm{E}-02 \\
5.89 \mathrm{E}-03 \\
4.73 \mathrm{E}-26 \\
1.01 \mathrm{E}-02 \\
1.26 \mathrm{E}-03 \\
8.12 \mathrm{E}-03 \\
7.56 \mathrm{E}-10\end{array}$ \\
\hline $\begin{array}{l}\text { Ethylene glycol } \\
\text { group (20 genes) }\end{array}$ & $\begin{array}{l}\text { Hr38 } \\
\text { Dh44 } \\
\text { CG12057 } \\
\text { CG17192 } \\
\text { CR43314 } \\
\text { Ets21C } \\
\text { CG8299 }\end{array}$ & $\begin{array}{l}2.46 \\
2.38 \\
1.84 \\
1.73 \\
1.49 \\
1.37 \\
1.36\end{array}$ & $\begin{array}{l}3.68 \mathrm{E}-05 \\
4.49 \mathrm{E}-05 \\
1.12 \mathrm{E}-06 \\
2.04 \mathrm{E}-07 \\
3.53 \mathrm{E}-05 \\
8.96 \mathrm{E}-05 \\
2.72 \mathrm{E}-05\end{array}$ & $\begin{array}{l}2.22 \mathrm{E}-02 \\
2.46 \mathrm{E}-02 \\
1.49 \mathrm{E}-03 \\
9.48 \mathrm{E}-04 \\
2.22 \mathrm{E}-02 \\
4.30 \mathrm{E}-02 \\
2.15 \mathrm{E}-02\end{array}$ \\
\hline
\end{tabular}

Table 2 Differentially expressed genes in NaOx and EG group compared with control (Continued)

\begin{tabular}{llll}
\hline Gene ID & $\begin{array}{l}\text { Log Fold } \\
\text { Change }\end{array}$ & $P$ value & FDR \\
\hline CG18744 & 1.35 & $7.85 \mathrm{E}-07$ & $1.36 \mathrm{E}-03$ \\
CG3036 & 1.25 & $8.81 \mathrm{E}-07$ & $1.36 \mathrm{E}-03$ \\
CG1718 & 1.21 & $3.01 \mathrm{E}-05$ & $2.15 \mathrm{E}-02$ \\
CG5404 & 1.20 & $4.35 \mathrm{E}-07$ & $1.35 \mathrm{E}-03$ \\
CG31324 & 1.16 & $8.84 \mathrm{E}-05$ & $4.30 \mathrm{E}-02$ \\
CG5151 & 1.09 & $3.80 \mathrm{E}-06$ & $4.42 \mathrm{E}-03$ \\
W & 1.03 & $9.25 \mathrm{E}-05$ & $4.30 \mathrm{E}-02$ \\
Jon66Ci & -1.19 & $2.92 \mathrm{E}-05$ & $2.15 \mathrm{E}-02$ \\
Jon66Cii & -1.38 & $7.94 \mathrm{E}-08$ & $7.38 \mathrm{E}-04$ \\
IM2 & -1.41 & $8.36 \mathrm{E}-06$ & $8.64 \mathrm{E}-03$ \\
CG5770 & -1.54 & $7.97 \mathrm{E}-07$ & $1.36 \mathrm{E}-03$ \\
Cpr49Ae & -2.94 & $3.83 \mathrm{E}-05$ & $2.22 \mathrm{E}-02$ \\
LysP & -3.63 & $1.05 \mathrm{E}-05$ & $9.78 \mathrm{E}-03$ \\
\hline
\end{tabular}

Positive log FC (Fold changes) denoted up regulation of genes whereas negative Log FC denoted down regulation FDR False detection Rate

concentration gradient ([18] Flybase). In the murine model, targeted disruption of renal sulfate transporter genes NaS1 and Sat1 leads to hyposulfatemia and hypersulfaturia. Loss of Sat1 leads to hyperoxaluria, hyperoxalemia and calcium oxalate urolithiasis $[19,20]$. These data suggest that sulfate transporters play an essential role for sulfate and oxalate homeostasis.

Similarly, the function of excitatory amino acid transporter (Eaat 1) as a sodium dicarboxylate symporter is inferred from homology to mammalian transporters. Its coding protein is an integral component of membrane which mediates concomitant uptake of sodium and dicarboxylate [21]. The rat ortholog of sodium dicarboxylate transporter $(\mathrm{NaDC})$ was reported to mediate citrate uptake from renal proximal tubule. Citrate is an important inhibitor of calcium-stone formation and most of the citrate reabsorption is thought to occur via a sodium dicarboxylate transporter $(\mathrm{NaDC} 1)$ located in the apical membrane. NaDC1 has been localized in opossum kidney proximal tubule cells and was responsible for calcium regulated citrate reabsorption in proximal tubules [22]. In the rat model, increased $\mathrm{NaDC} 1$ expression on the renal proximal tubule epithelial cells was associated with a decline in urinary citrate excretion, suggesting this transporter could play an important role in nephrolithiasis development [23]. In our study, Eaat1 demonstrated decreased expression in sodium oxalate diets compared with control, suggesting a protective effect to tubular stone formation.

The other candidate gene, Crystallin encodes a calcium ion binding protein [24] and is a major structural constituent of eye lens [25]. The implication of this gene in the biological process of stone formation is yet to be elucidated.

Similarly, in the EG treatment group, the protein products of gene CG3036 and CG5404 work as transmembrane transporter i.e. sodium-phosphate symporter and 


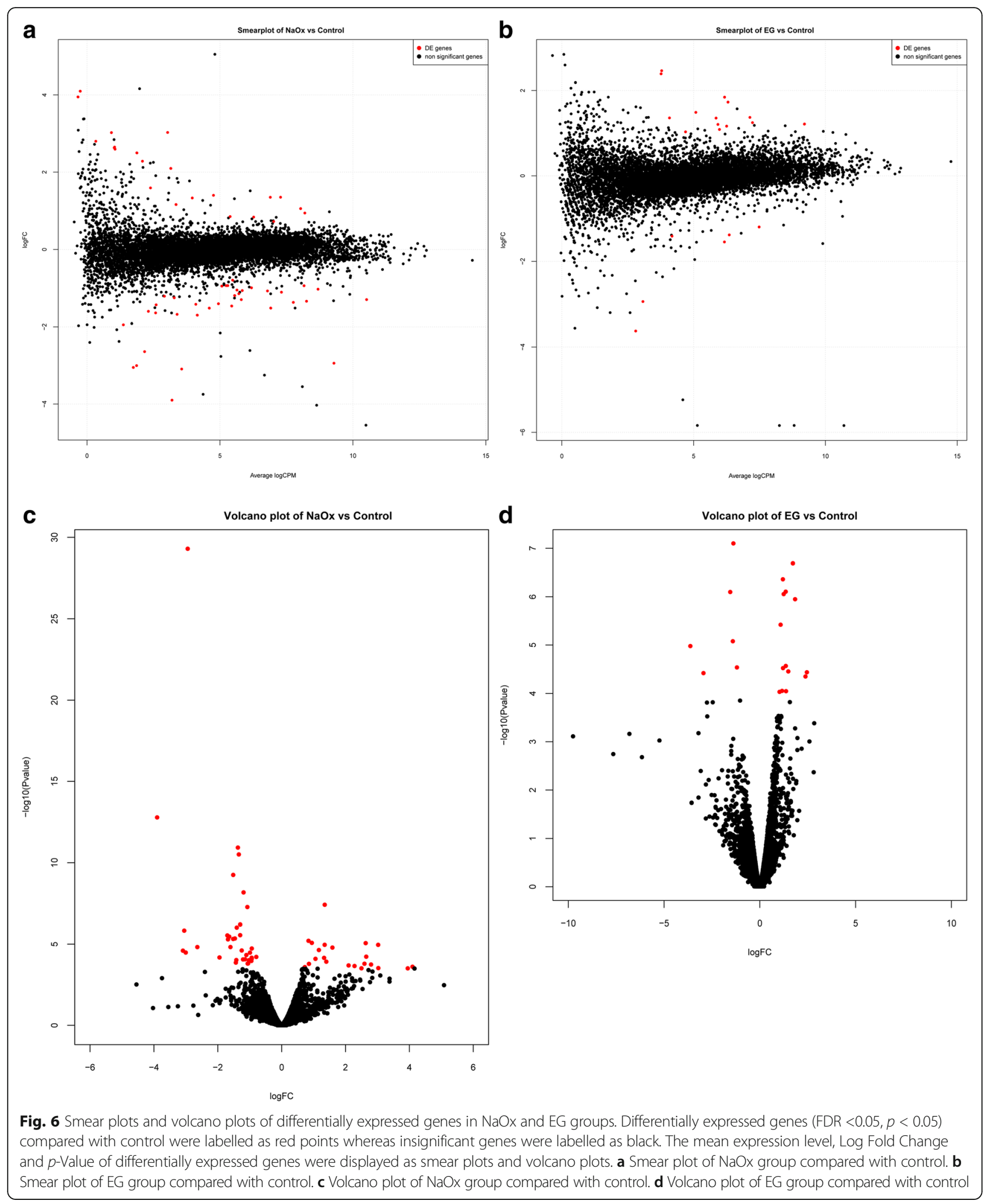




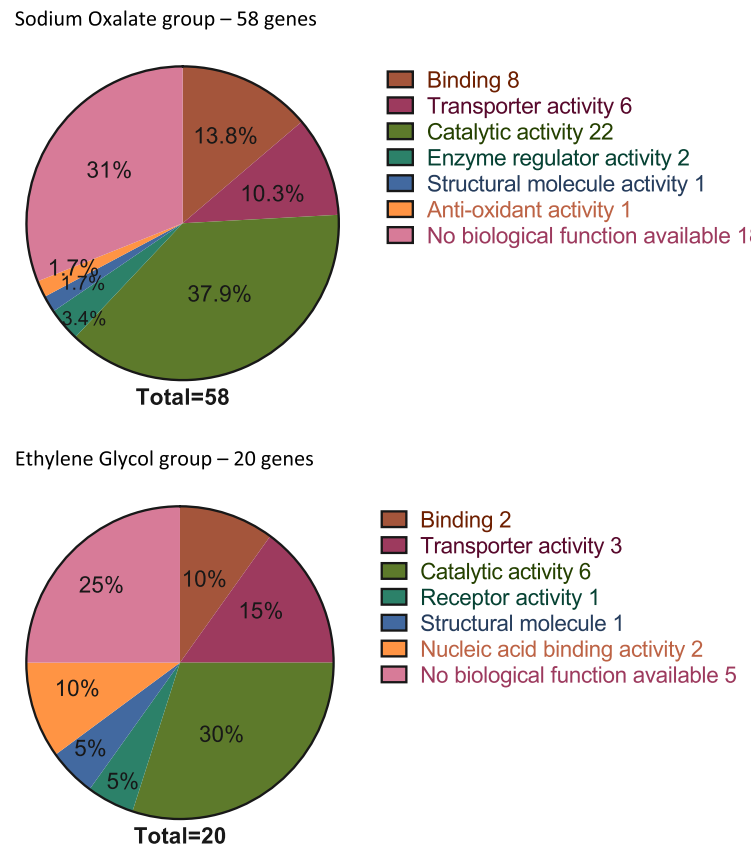

Fig. 7 Molecular functions of differentially expressed genes

high affinity sulfate transmembrane transporter, despite that the function of these gene products has not been directly measured Sodium phosphate co-transporter (Npt2a) null mice are shown to have hypercalciuria and hyperphosphaturia, and develop tubular and interstitial Ca phosphate deposits [26]. Crystals of $\mathrm{CaOx}$ may result for nucleation surrounding the Ca phosphate crystal [27] In human, hypophosphatemic hypercalciuric nephrolithiasis associated with rickets is the related to mutations in the type 2c sodium-phosphate co-transporter [28]. The up regulation of CG3036 in Drosophila might be a counteractive response to lower down tubular $\mathrm{Ca}$ level to reduce $\mathrm{CaOx}$ stone formation.

$\mathrm{Dh} 44$ is a gene that encodes a corticotrophin releasing factor (CRF) like peptide with 44 amino acids. Functional studies showed that the protein product stimulated fluid production, and this effect was mediated by cyclic AMP in principal cells only [29]. The significant up regulation of this diuretic hormone in Malpighian tubules could be a direct protective effect of body fluid secretion in response to crystal formation.

These differentially expressed genes could play a role in the biological pathway of calcium oxalate stone formation or could be a regulated response to the obstructive uropathy, metabolic acidosis and failure to maintain electrolyte or acidbase balance in Drosophila Malpighian tubules. We made the hypothesis that genes encoding transmembrane ion transporter or diuretic hormone might be more critical in these processes but other genes might also be relevant. Molecular function of many differentially expressed genes remained unknown, so that further investigations will be required to elucidate the exact roles of these genes and how they function as a whole in the process of $\mathrm{CaOx}$ crystal formation.

Despite the high incidence of crystal formation in flies fed with lithogenic agents, we do not know if there was any difference in the transcriptive changes in stone formers and non-stone former. Experiments designed to study the difference of stone-formers and non-stone formers might provide further insight in the pathogenesis.

In this experiment of environmentally induced stone formation, we have successfully used the drosophila as a model to demonstrate transcriptional changes in a number of genes that may play a role in the pathogenesis of stone formation. To evaluate the contribution of these genes to stone formation, RNAi could be used to preform tissue-specific knockdown or overexpression studies to modify stone formation, using the extensive collection of genetic reagents available in Drosophila. Downstream proteomic analysis could further provide information of the function of possible candidate genes.

\section{Conclusions}

Our results suggest that drosophila proved to be a powerful experimental organism for studying nephrolithiasis. The transcriptome secondary to crystal formation could provide useful insight into the pathophysiology of stone formation and potential therapeutic target for the treatment of nephrolithiasis.

Table 3 Candidate genes which function as transmembrane ion transporter, Ca ion binder or diuretic hormone that may play a role in crystal formation

\begin{tabular}{llll}
\hline & Gene name & GO Molecular function & Log FC \\
\hline Sodium oxalate group & nervana 3 & plasma membrane Na:K- exchanging ATPase activity & -1.29 \\
& Excitatory amino acid transporter 1 & Na: dicarboxylate symporter activity; Na:glutamate symporter activity & -0.93 \\
& CG7912 & High affinity Sulfate transmembrane transporter & -1.25 \\
& Crystallin & Ca ion binding & 0.945 \\
Ethylene Glycol group & CG3036 & Na: phosphate symporter activity & 1.24 \\
& CG5404 & high affinity sulfate transmembrane transporter & 1.2 \\
& Dh44 & Diuretic hormone activity & 2.38 \\
\hline
\end{tabular}




\section{Abbreviations}

CaOx: Calcium oxalate; EG: Ethylene glycol; FC: Fold changes; FDR: False discovery rate; mRNA: Messenger RNA; NaOx: Sodium oxalate; rRNA: Ribosomal RNA

\section{Acknowledgements}

We appreciate the help of Dr. Markus Toegel, Dr. Tudor Fulga from Weatherall Institute of Molecular Medicine, University of Oxford for the generous support during the experiments. We thank the High-Throughput Genomics Group at the Wellcome Trust Centre for Human Genetics (funded by Wellcome Trust grant reference 090532/Z/09/Z and MRC Hub grant G0900747 91070) for the generation of the sequencing data. We also appreciate the help of Mr. Mark Sullivan and Dr. Rebecca Konietzny for reviewing the manuscript.

\section{Funding}

Not applicable.

\section{Availability of data and materials}

The datasets used and analyzed during the current study are available from the corresponding author on reasonable request.

\section{Authors' contributions}

VC prepared the experiment samples, participated in the RNA sequencing, carried out data analysis and drafted the manuscript. BT designed the study, participated in data analysis and manuscript revision. Both authors read and approved the final manuscript.

\section{Ethics approval and consent to participate}

This study does not involve human subjects or patients. Drosophila, which is an unprotected species, was used as experimental material. Ethic approval is not applicable.

\section{Consent for publication}

Not applicable.

\section{Competing interests}

The authors declare that they have no competing interests.

\section{Publisher's Note}

Springer Nature remains neutral with regard to jurisdictional claims in published maps and institutional affiliations.

Received: 4 November 2015 Accepted: 30 October 2017

Published online: 28 November 2017

\section{References}

1. Turney BW, Reynard JM, Noble JG, Keoghane SR. Trends in urological stone disease. BJU Int. 2012;109(7):1082-7.

2. Scales CD Jr, Smith AC, Hanley JM, Saigal CS. Prevalence of kidney stones in the United States. Eur Urol. 2012;62(1):160-5.

3. Curhan GC, Willett WC, Rimm EB, Stampfer MJ. A prospective study of dietary calcium and other nutrients and the risk of symptomatic kidney stones. N Engl J Med. 1993;328(12):833-8.

4. Resnick M, Pridgen DB, Goodman HO. Genetic predisposition to formation of calcium oxalate renal calculi. N Engl J Med. 1968;278(24):1313-8.

5. Miller J, Chi T, Kapahi P, Kahn AJ, Kim MS, Hirata T, et al. Drosophila Melanogaster as an emerging translational model of human nephrolithiasis. J Urol. 2013;190(5):1648-56.

6. Chen YH, Liu HP, Chen HY, Tsai FJ, Chang CH, Lee YJ, et al. Ethylene glycol induces calcium oxalate crystal deposition in Malpighian tubules: a drosophila model for nephrolithiasis/urolithiasis. Kidney Int. 2011;80(4):369-77.

7. Winnebeck EC, Millar CD, Warman GR. Why does insect RNA look degraded? J Insect Sci. 2010;10:159.

8. Hirata T, Cabrero P, Berkholz DS, Bondeson DP, Ritman EL, Thompson JR, et al. In vivo Drosophilia genetic model for calcium oxalate nephrolithiasis. Am J Physiol Renal Physiol. 2012;303(11):F1555-62.

9. Dow JA, Romero MF. Drosophila provides rapid modeling of renal development, function, and disease. Am J Physiol Renal Physiol. 2010;299(6):F1237-44.

10. Beyenbach KW. Transport mechanisms of diuresis in Malpighian tubules of insects. J Exp Biol. 2003;206(Pt 21):3845-56.
11. Wessing A, Zierold K. The formation of type-I concretions in drosophila Malpighian tubules studied by electron microscopy and X-ray microanalysis. J Insect Physiol. 1999;45(1):39-44.

12. Leth PM, Gregersen M. Ethylene glycol poisoning. Forensic Sci Int. 2005; 155(2-3):179-84

13. Sun B, Wang W, Salvaterra PM. Functional analysis and tissue-specific expression of Drosophila Na+,K+-ATPase subunits. J Neurochem. 1998;71(1):142-51.

14. Friedman PA. Codependence of renal calcium and sodium transport. Annu Rev Physiol. 1998;60:179-97.

15. Gmaj P, Murer H, Kinne R. Calcium ion transport across plasma membranes isolated from rat kidney cortex. Biochem J. 1979:178(3):549-57.

16. Friedman PA, Figueiredo JF, Maack T, Windhager EE. Sodium-calcium interactions in the renal proximal convoluted tubule of the rabbit. Am J Phys. 1981;240(6):F558-68.

17. Winkfein RJ, Pearson B, Ward R, Szerencsei RT, Colley NJ, Schnetkamp PP. Molecular characterization, functional expression and tissue distribution of a second NCKX Na+/Ca2+ -K+ exchanger from drosophila. Cell Calcium. 2004:36(2):147-55.

18. dos Santos G, Schroeder AJ, Goodman JL, Strelets VB, Crosby MA, Thurmond J, et al. FlyBase: introduction of the Drosophila Melanogaster release 6 reference genome assembly and large-scale migration of genome annotations. Nucleic Acids Res. 2015:43(Database issue):D690-7.

19. Markovich D. Physiological roles of mammalian sulfate transporters NaS1 and Sat1. Arch Immunol Ther Exp. 2011:59(2):113-6.

20. Dawson PA, Russell CS, Lee S, McLeay SC, van Dongen JM, Cowley DM, et al. Urolithiasis and hepatotoxicity are linked to the anion transporter Sat1 in mice. J Clin Invest. 2010;120(3):706-12.

21. Reizer J, Reizer A, Saier MH Jr. A functional superfamily of sodium/solute symporters. Biochim Biophys Acta. 1994;1197(2):133-66.

22. Hering-Smith KS, Mao W, Schiro FR, Coleman-Barnett J, Pajor AM, Hamm LL. Localization of the calcium-regulated citrate transport process in proximal tubule cells. Urolithiasis. 2014;42(3):209-19.

23. He Y, Chen $X, Y u Z$, Wu D, LV Y, Shi S, et al. Sodium dicarboxylate cotransporter-1 expression in renal tissues and its role in rat experimental nephrolithiasis. J Nephrol. 2004;17(1):34-42.

24. Srivastava SS, Mishra A, Krishnan B, Sharma Y. Ca2+-binding motif of betagamma-crystallins. J Biol Chem. 2014;289(16):10958-66.

25. Jobby MK, Sharma Y. Calcium-binding to lens betaB2- and betaA3-crystallins suggests that all beta-crystallins are calcium-binding proteins. FEBS J. 2007:274(16):4135-47.

26. Khan SR, Canales BK. Ultrastructural investigation of crystal deposits in Npt2a knockout mice: are they similar to human Randall's plaques? J Urol. 2011;186(3):1107-13.

27. Tiselius HG. A hypothesis of calcium stone formation: an interpretation of stone research during the past decades. Urol Res. 2011;39(4):231-43.

28. Stechman MJ, Loh NY, Thakker RV. Genetic causes of hypercalciuric nephrolithiasis. Pediatr Nephrol. 2009;24(12):2321-32.

29. Cabrero P, Radford JC, Broderick KE, Costes L, Veenstra JA, Spana EP, et al. The Dh gene of Drosophila Melanogaster encodes a diuretic peptide that acts through cyclic AMP. J Exp Biol. 2002;205(Pt 24):3799-807.

\section{Submit your next manuscript to BioMed Central and we will help you at every step:}

- We accept pre-submission inquiries

- Our selector tool helps you to find the most relevant journal

- We provide round the clock customer support

- Convenient online submission

- Thorough peer review

- Inclusion in PubMed and all major indexing services

- Maximum visibility for your research

Submit your manuscript at www.biomedcentral.com/submit
C) BioMed Central 